\title{
Analisis Jaringan Syaraf Tiruan untuk prediksi volume ekspor dan impor migas di Indonesia
}

\author{
Yuli Andriani a, Hotmalina Silitonga ${ }^{b}$, Anjar Wanto ${ }^{c}$ \\ a,b,c Teknik Informatika, STIKOM Tunas Bangsa, Pematangsiantar, Indonesia \\ email:a andrianiyuli66@gmail.com,bhotmalinasilitonga22@gmail.com,canjards@amiktunasbangsa.ac.id
}

\begin{tabular}{l}
\hline I N F O A R T I K E L \\
\hline Sejarah artikel: \\
Menerima 15 Mei 2018 \\
Revisi 8 Agustus 2018 \\
Diterima 8 Agustus 2018 \\
Online 8 Agustus 2018 \\
\hline Kata kunci: \\
ekspor \\
impor \\
Jaringan Syaraf Tiruan \\
migas Ilmiah \\
prediksi \\
\hline Keywords: \\
ANN \\
declaration form \\
impor export declaration \\
oil and gas \\
predictions \\
Style APA dalam mensitasi \\
artikel ini: \\
Andriani, Y., Silitonga, H., \& \\
Wanto, A. (2018). Analisis \\
Jaringan Syaraf tiruan untuk \\
prediksi volume ekspor dan \\
impor migas di Indonesia. \\
Register: Jurnal \\
Teknologi Sistem Informasi, \\
4(1), 30-40. \\
\end{tabular}

\begin{abstract}
ABSTRAK
Analisis pada penelitian penting dilakukan untuk tujuan mengetahui ketepatan dan keakuratan dari penelitian itu sendiri. Begitu juga dalam prediksi volume ekspor dan impor migas di Indonesia. Dilakukannya penelitian ini untuk mengetahui seberapa besar perkembangan ekspor dan impor Indonesia di bidang migas di masa yang akan datang. Penelitian ini menggunakan Jaringan Syaraf Tiruan (JST) atau Artificial Neural Network (ANN) dengan algoritma Backpropagation. Data penelitian ini bersumber dari dokumen kepabeanan Ditjen Bea dan Cukai yaitu Pemberitahuan Ekspor Barang (PEB) dan Pemberitahuan Impor Barang (PIB). Berdasarkan data ini, variabel yang digunakan ada 7, antara lain: Tahun, ekspor minyak mentah, impor minyak mentah, ekspor hasil minyak, impor hasil minyak, ekspor gas dan impor gas. Ada 5 model arsitektur yang digunakan pada penelitian ini, 12-5-1, 12-7-1, 12-8-1, 12-10-1 dan 12-14-1. Dari ke 5 model yang digunakan, yang terbaik adalah 12-5-1 dengan menghasilkan tingkat akurasi 83\%, MSE 0,0281641257 dengan tingkat error yang digunakan 0,001-0,05. Sehingga model ini bagus untuk memprediksi volume ekspor dan impor migas di Indonesia, karena akurasianya antara 80\% hingga 90\%.
\end{abstract}

\section{ABSTRACT}

Analysis of the research is Imporant used to know precision and accuracy of the research itself. It is also in the prediction of Volume Exports and Impors of Oil and Gas in Indonesia. This research is conducted to find out how much the development of Indonesia's exports and Impors in the field of oil and gas in the future. This research used Artificial Neural Network with Backpropagation algorithm. The data of this research have as a source from custom documents of the Directorate General of Customs and Excise (Declaration Form/PEB and Impor Export Declaration/PIB). Based on this data, there are 7 variables used, among others: Year, Crude oil exports, Crude oil Impors, Exports of oil products, Impored oil products, Gas exports and Gas Impors. There are 5 architectural models used in this study, 12-5-1, 12-7-1, 12-8-1, 12-10-1 and 12-14-1. Of the 5 models has used, the best models is 12-5-1 with an accuracy 83\%, MSE 0.0281641257 with error rate 0.001 0.05. So this model is good to predict the Volume of Exports and Impors of Oil and Gas in Indonesia, because its accuracy between $80 \%$ to $90 \%$.

(c) 2018 Register: Jurnal IImiah Teknologi Sistem Informasi. Semua hak cipta dilindungi undang-undang.

\section{Pendahuluan}

Indonesia adalah negara dengan kekayaan sumber daya alam yang melimpah. Sumber daya alam Indonesia salah satunya berasal dari pertambangan dan energi. Pertambangan menjadi salah satu aspek andalan yang harus dikelola secara baik oleh Indonesia. Pertambangan dilakukan dengan mengeksplorasi mineral yang terkandung di bumi Indonesia (Rumokoy, 2016). Pertambangan yang dimiliki Indonesia salah satunya yakni tambang minyak dan gas (migas). Sektor migas ini merupakan salah satu andalan bagi Indonesia untuk mendapatkan devisa negara dalam rangka mendukung kelangsungan pembangunan (Setiawan, Taufiq, \& Astrika, 2017). Oleh karena itu, pemerintah dituntut untuk mengelola migas dengan baik. Apalagi minyak bumi dan gas sudah menjadi barang yang sangat dibutuhkan oleh manusia. Bahkan hampir semua fasilitas yang dinikmati manusia, khususnya di 
Indonesia sekarang ini harus menggunakan minyak bumi dan gas alam,_seperti kebutuhan rumah tangga, transportasi, listrik, maupun kebutuhan industri atau usaha (Annuri \& Ruzikna, 2017).

Perkembangan sektor migas di Indonesia sangat berdinamika. Indonesia dan negara-negara di dunia terpaksa menyesuaikan produksi, konsumsi, kebijakan baik dalam dan luar negeri yang diakibatkan perubahan harga minyak dunia dari waktu kewaktu, agar tetap tercapainya kesejahteraan rakyat. Apalagi produksi dan cadangan migas kita semakin lama semakin menurun. Walaupun cadangan gas kita empat kali lipat dibandingkan dengan minyak, akan tetapi program konversi dari minyak ke gas domestik tidaklah berjalan mulus. Oleh karena itu, ada kalanya pada tiap tahunnya kita harus mengimpor migas, ada kalanya juga mengekspor. Jumlah ekspor migas yang naik turut menyebabkan nilai tukar Rupiah menguat, mengakibatkan permintaan akan mata uang domestik yang juga naik (Sedyaningrum, Suhadak, \& Nuzula, 2016).

Pada Tabel 1 dapat dilihat bahwa adanya ketimpangan yang cukup signifikan antara ekspor maupun impor, baik dari segi minyak mentah, hasil minyak maupun gas. Volume ekspor minyak mentah dari tahun 1996 hingga tahun 2016 mengalami penurunan yang cukup besar, sedangkan volume impor semakin lama semakin tinggi. Begitu juga terhadap hasil minyak maupun gas. Kalau hal ini semakin dibiarkan, maka akan berdampak terhadap tingkat perekonomian bangsa Indonesia di masa yang akan datang.

Tabel 1. Data volume ekspor dan impor migas di Indonesia (Ribu ton) (BPS, 2017)

\begin{tabular}{|c|c|c|c|c|c|c|}
\hline \multirow{2}{*}{ Tahun } & \multicolumn{2}{|c|}{ Minyak Mentah } & \multicolumn{2}{|c|}{ Hasil Minyak } & \multicolumn{2}{|c|}{ Gas } \\
\hline & Ekspor & Impor & Ekspor & Impor & Ekspor & Impor \\
\hline 1996 & 38254,9 & 9349,9 & 10689,3 & 10133,8 & 29343,6 & 1,3 \\
\hline 1997 & 38976,5 & 9125,5 & 10220,8 & 11747,7 & 29015,6 & 31,6 \\
\hline 1998 & 36914,0 & 10473,3 & 8435,9 & 10941,0 & 28953,5 & 86,0 \\
\hline 1999 & 35902,5 & 11497,4 & 7825,4 & 12249,9 & 30066,3 & 25,8 \\
\hline 2000 & 29225,9 & 11473,5 & 8786,6 & 13971,0 & 27615,2 & 11,2 \\
\hline 2001 & 32857,0 & 14174,9 & 7007,8 & 11750,5 & 25235,6 & 30,6 \\
\hline 2002 & 29054,4 & 15880,0 & 7574,0 & 15116,0 & 27617,7 & 0,2 \\
\hline 2003 & 26517,5 & 16817,2 & 7425,0 & 13588,6 & 27613,7 & 69,3 \\
\hline 2004 & 23467,8 & 18930,4 & 6800,4 & 15971,5 & 26594,3 & 18,7 \\
\hline 2005 & 21488,0 & 15649,7 & 5994,0 & 21065,2 & 24445,4 & 22,5 \\
\hline 2006 & 18127,9 & 14642,5 & 7046,9 & 18657,8 & 23116,7 & 48,6 \\
\hline 2007 & 18175,3 & 15146,7 & 6264,8 & 19475,7 & 21270,8 & 116,9 \\
\hline 2008 & 18235,0 & 12749,0 & 5724,0 & 22391,2 & 20841,9 & 336,2 \\
\hline 2009 & 17967,1 & 15303,7 & 5405,7 & 19732,0 & 22700,1 & 970,8 \\
\hline 2010 & 18132,4 & 14249,6 & 7322,8 & 25123,9 & 30469,9 & 1126,0 \\
\hline 2011 & 17819,5 & 13253,6 & 6931,5 & 28840,3 & 34302,9 & 1633,9 \\
\hline 2012 & 14973,1 & 12550,1 & 5629,5 & 28534,5 & 27843,3 & 3170,4 \\
\hline 2013 & 13016,9 & 16015,6 & 5914,5 & 29612,2 & 25110,4 & 3425,9 \\
\hline 2014 & 12400,0 & 16185,9 & 5556,9 & 29093,6 & 23786,2 & 3589,9 \\
\hline 2015 & 15554,1 & 18727,6 & 4625,8 & 25404,7 & 24784,8 & 4176,8 \\
\hline 2016 & 16955,5 & 19932,3 & 2868,1 & 23958,3 & 23505,2 & 4435,2 \\
\hline
\end{tabular}

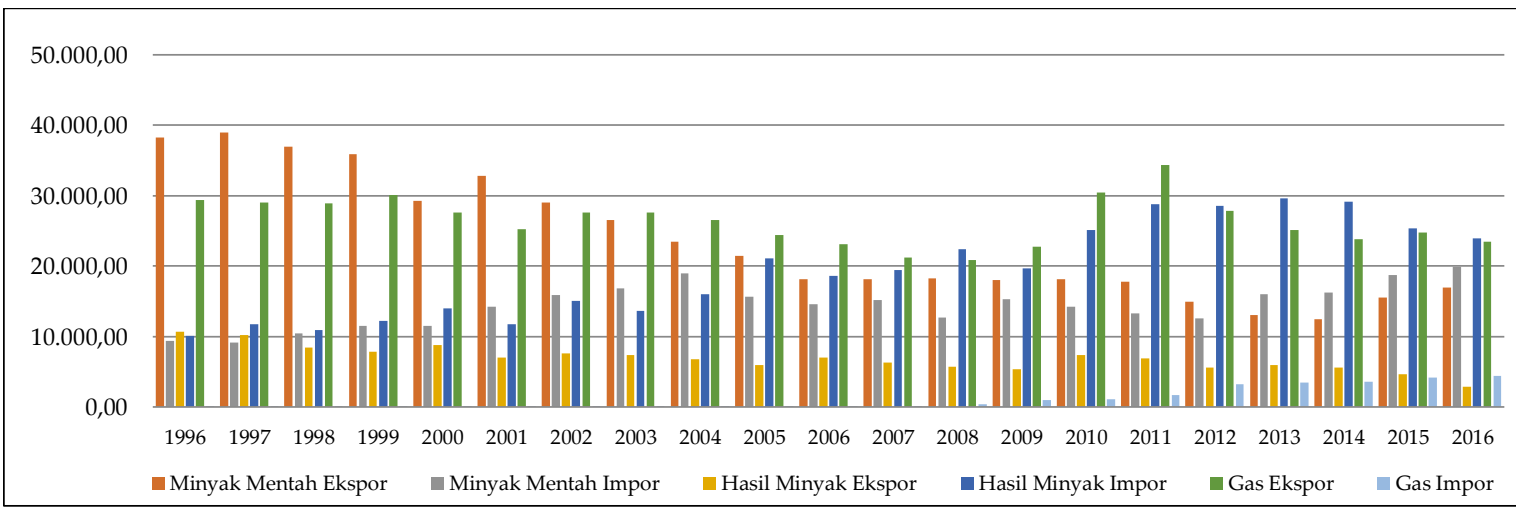

Gambar 1. Grafik volume ekspor dan impor migas di Indonesia 
Berdasarkan Gambar 1 dapat dijelaskan bahwa volume ekspor minyak mentah semakin menurun dari tahun 1996 hingga tahun 2016, sedangkan volume impor semakin naik. Begitu pula halnya terhadap hasil minyak maupun gas. Volume ekspor minyak mentah tertinggi terdapat pada tahun 1997 dan yang terendah tahun 2014, sedangkan volume impor minyak mentah tertinggi pada tahun 2016. Berdasarkan ekspor hasil minyak, volume tertinggi terdapat pada tahun 1996 dan terendah tahun 2016, sedangkan volume impor minyak mentah tertinggi pada tahun 2013. Berdasarkan ekspor gas, volume tertinggi terdapat pada tahun 2011 dan terendah tahun 2008, sedangkan volume impor gas tertinggi pada tahun 2016.

Oleh sebab itu, salah satu cara yang dapat dilakukan untuk menekan angka volume ekspor dan impor migas di Indonesia agar tetap stabil yaitu dengan langkah prediksi (peramalan) terhadap perkembangan volume ekspor dan impor migas di Indonesia untuk tahun berikutnya. Dengan demikian, sedini mungkin pihak pemerintah pusat diharapkan mampu menentukan kebijakan yang tepat untuk mengatasinya. Tetapi melakukan prediksi tidaklah mudah, dibutuhkan data-data terdahulu yang berhubungan dengan masalah yang akan diprediksi, hal ini umumnya rumit dan tidak mudahnya dicapai keakuratan dari estimasi, sehingga membutuhkan teknik yang lebih maju. Teknik yang sering digunakan untuk melakukan prediksi yakni algoritma Backpropagation, karena algoritma ini mampu memprediksi data dengan menggunakan aturan pembelajaran berdasarkan data-data yang sudah pernah terjadi sebelumnya.

\section{State of the Art}

\subsection{Algoritma Backpropagation}

Algoritma Backpropagation telah menjadi algoritma pembelajaran yang terkenal di antara Jaringan Syaraf Tiruan (JST) atau Artificial Neural Network (ANN) lainnya, telah diterapkan secara luas dan sukses dalam berbagai aplikasi, seperti pemilihan lokasi, pengenalan pola maupun evaluasi kinerja (Sumijan, Windarto, Muhammad, \& Budiharjo, 2016). Algoritma Backpropagation melibatkan tiga lapisan: Input layer, berfungsi memasukkan data ke jaringan; Hidden layer, sebagai tempat pemrosesan data; dan Output layer berfungsi sebagai luaran hasil input (Huang \& Wu, 2017) (Alqurni \& Muljono, 2016). Metode training Backpropagation melibatkan feedforward dari pola training input, perhitungan dan Backpropagation kesalahan, dan penyesuaian bobot dalam sinapsis (Wang, Gong, Li, Li, \& Zhang, 2017).

\subsection{Prediksi (Peramalan)}

Prediksi (peramalan) adalah usaha memperkirakan dan menduga hal yang akan terjadi di masa mendatang berdasarkan hal-hal yang telah terjadi di waktu-waktu sebelumnya (historis) melalui suatu metode ilmiah dengan memanfaatkan berbagai informasi yang relevan. Tujuan dari prediksi adalah mendapatkan informasi apa yang akan terjadi di masa datang dengan probabilitas kejadian terbesar. Metode prediksi dapat dilakukan secara kualitatif melalui pendapat para pakar atau secara kuantitatif dengan perhitungan secara matematis. Salah satu metode prediksi kuantitatif adalah menggunakan analisis deret waktu (time series) (Siregar \& Wanto, 2017).

\subsection{Penelitian Sebelumnya}

Pada penelitian Wanto, Windarto, Hartama, dan Parlina (2017) telah dilakukan penelitian untuk memprediksi Kepadatan Penduduk menggunakan JST Backpropagation dengan menerapkan fungsi aktivasi sigmoid biner dan linier (purelin). Penelitian ini menghasilkan prediksi dengan akurasi sebesar 94\%. Izzah dan Widyastuti (2016) telah dilakukan penelitian untuk memprediksi kelulusan mata kuliah menggunakan hybrid fuzzy inference system. Penelitian ini menghasilkan akurasi sebesar 94,33\%, sensitifitas 96,55\% dan spesifisitas 84,21\%. Hidayat, Musadieq, dan Darmawan (2017) telah dilakukan penelitian untuk melihat faktor-faktor apa saja yang mempengaruhi nilai ekspor non migas di Indonesia, serta sejauh mana pengaruh langsung investasi asing, pertumbuhan ekonomi maupun nilai tukar terhadap ekspor. Oleh sebab itu, berdasarkan penelitian sebelumnya, maka penelitian kali ini akan menggunakan metode Backpropagation untuk memprediksi volume ekspor dan impor migas di Indonesia.

\section{Metode Penelitian}

\subsection{Sumber data}

Analisis jst untuk prediksi volume ekspor dan impor migas ... https://doi.org/10.26594/register.v4i1.1157

(c) 2018 Register: Jurnal Ilmiah Teknologi Sistem Informasi. Semua hak cipta dilindungi undang-undang. 
Penelitian ini menggunakan data Volume Ekspor dan Impor Migas di Indonesia yang diperoleh dari Badan Pusat Statistik (BPS) Indonesia yang diolah berdasarkan dokumen dari kepabeanan Ditjen Bea dan Cukai tahun 1996 hingga 2016 (BPS, 2017).

\subsection{Kerangka kerja penelitian}

Secara umum, metode penelitian yang digunakan dalam penelitian ini berdasarkan pada kerangka kerja pada Gambar 2. Kerangkan kerja digunakan untuk menguraikan dan menyelesaikan masalah dalam penelitian.

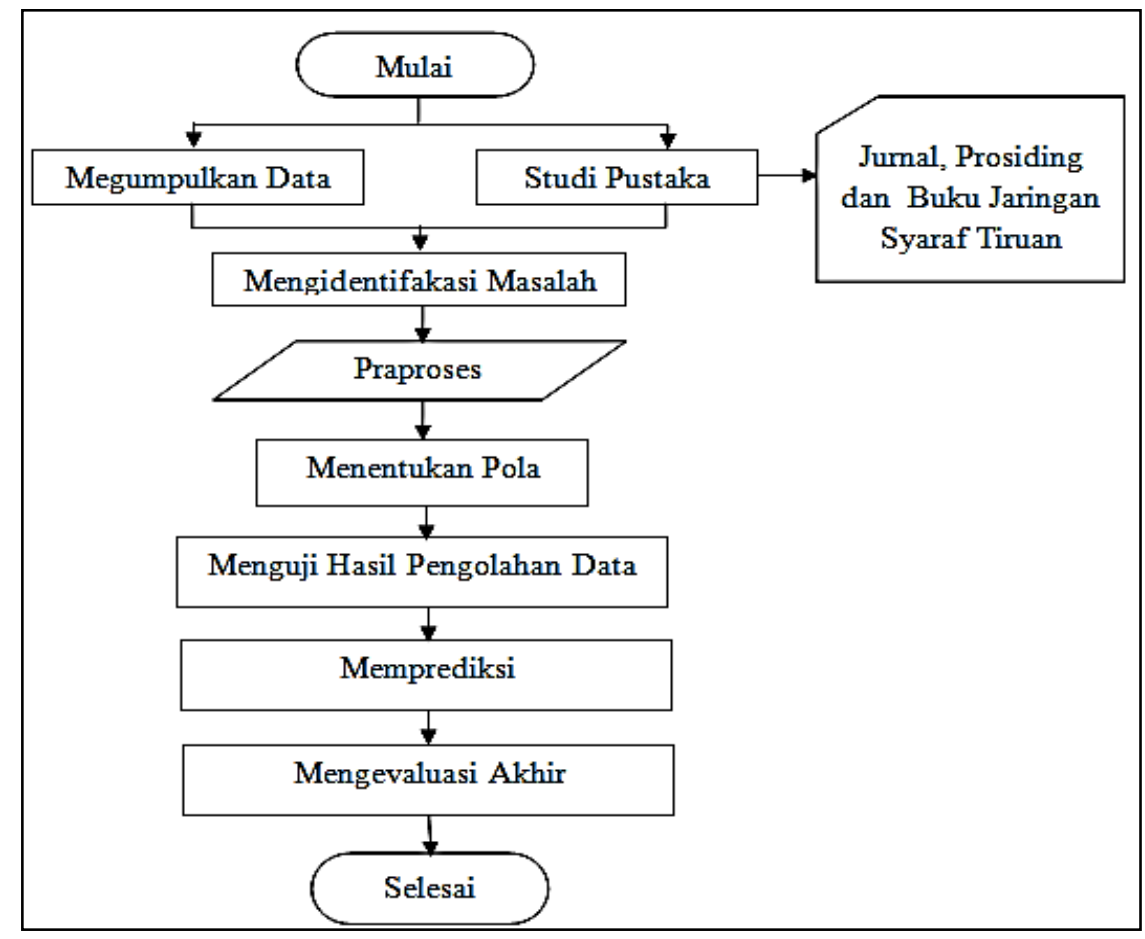

Gambar 2. Kerangka kerja penelitian

Dari kerangka kerja Gambar 2 dapat dijelaskan bahwa mengumpulkan data di dalam suatu penelitian merupakan hal pertama yang harus dilakukan. Tahap kedua dilakukan studi pustaka untuk melengkapi pengetahuan dasar dan teori-teori yang digunakan dalam penelitian ini. Tahap ketiga melakukan identifikasi masalah untuk memproses tahap konversi data yang diperoleh sesuai dengan bobot yang telah ditentukan. Tahapan keempat praproses dengan tujuan untuk mempermudah pemahaman terhadap isi record. Tahap kelima menentukan pola maupun penentuan model arsitektur jaringan yang disesuaikan dengan masalah penelitian yang dihadapi. Tahap keenam menguji hasil pengolahan data dengan menggunakan aplikasi Matlab. Tahapan ketujuh memprediksi, yakni untuk melihat perbandingan dari beberapa model arsitektur yang digunakan pada penelitian sehingga diperoleh model arsitektur terbaik serta tingkat akurasi yang paling akurat. Tahap kedelapan mengevaluasi akhir untuk mengetahui apakah hasil pengolahan data sudah sesuai seperti yang diinginkan.

\subsection{Data Normalisasi}

Data awal yang telah dikumpulkan akan dinormalisasi dengan menggunakan rumus normalisasi yang akan menghasilkan nilai antara 0 dan 1 , hal ini dilakukan sesuai dengan ketentuan normalisasi pada Persamaan (1).

$x^{\prime}=\frac{0.8(x-a)}{b-a}+0.1$

di mana $x^{\prime}$ adalah data yang telah dinormalisasi, $x$ adalah data yang dinormalisasi, $a$ adalah data yang nilainya paling kecil, dan $b$ adalah data maksimal yang nilainya paling besar.

Pada JST Backpropagation, data yang berdasarkan Tabel 1 nantinya dibagi kedalam dua bagian, yakni data pelatihan (training) dan data pengujian (testing). Data pelatihan (training) yang akan 

(testing) dimulai dari tahun 2004-2015 dengan target tahun 2016.

Hasil normalisasi data training dapat dilihat pada Tabel 2. Data ini telah dinormalisasi menggunakan rumus normalisasi seperti yang dijelaskan pada Persamaan (1) berdasarkan pada Tabel 1, yakni tahun 1996-2007 dengan target tahun 2008.

Tabel 2. Normalisasi data training (Tahun 1996-2007) / Target Tahun 2008

\begin{tabular}{ccccccc}
\hline \multirow{2}{*}{ Tahun } & \multicolumn{2}{c}{ Minyak Mentah } & \multicolumn{2}{c}{ Hasil Minyak } & \multicolumn{2}{c}{ Gas } \\
\cline { 2 - 7 } & Ekspor & Impor & Ekspor & Impor & Ekspor & Impor \\
\hline 1996 & 0,88519 & 0,29191 & 0,31940 & 0,30800 & 0,70228 & 0,10002 \\
1997 & 0,90000 & 0,28730 & 0,30978 & 0,34112 & 0,69555 & 0,10064 \\
1998 & 0,85767 & 0,31496 & 0,27315 & 0,32456 & 0,69427 & 0,10176 \\
1999 & 0,83691 & 0,33598 & 0,26061 & 0,35143 & 0,71712 & 0,10053 \\
2000 & 0,69987 & 0,33549 & 0,28034 & 0,38675 & 0,66681 & 0,10023 \\
2001 & 0,77440 & 0,39094 & 0,24383 & 0,34118 & 0,61796 & 0,10062 \\
2002 & 0,69635 & 0,42594 & 0,25545 & 0,41026 & 0,66686 & 0,10000 \\
2003 & 0,64428 & 0,44517 & 0,25240 & 0,37891 & 0,66678 & 0,10142 \\
2004 & 0,58168 & 0,48855 & 0,23958 & 0,42782 & 0,64585 & 0,10038 \\
2005 & 0,54104 & 0,42121 & 0,22302 & 0,53237 & 0,60174 & 0,10046 \\
2006 & 0,47208 & 0,47208 & 0,24464 & 0,48295 & 0,57447 & 0,10099 \\
2007 & 0,47305 & 0,41089 & 0,22858 & 0,49974 & 0,53659 & 0,10240 \\
\hline Target & 0,47427 & 0,36167 & 0,21748 & 0,55958 & 0,52778 & 0,10690 \\
\hline
\end{tabular}

Tabel 3. Normalisasi data testing (Tahun 2004-2015) / Target Tahun 2016

\begin{tabular}{ccccccc}
\hline \multirow{2}{*}{ Tahun } & \multicolumn{2}{c}{ Minyak Mentah } & \multicolumn{2}{c}{ Hasil Minyak } & \multicolumn{2}{c}{ Gas } \\
\cline { 2 - 7 } & Ekspor & Impor & Ekspor & Impor & Ekspor & Impor \\
\hline 2004 & 0,64717 & 0,54129 & 0,25825 & 0,47225 & 0,72012 & 0,10000 \\
2005 & 0,60097 & 0,46474 & 0,23943 & 0,59111 & 0,66998 & 0,10009 \\
2006 & 0,52257 & 0,52257 & 0,26400 & 0,53493 & 0,63898 & 0,10070 \\
2007 & 0,52367 & 0,45300 & 0,24575 & 0,55402 & 0,59590 & 0,10229 \\
2008 & 0,52507 & 0,39705 & 0,23313 & 0,62205 & 0,58590 & 0,10741 \\
2009 & 0,51881 & 0,45667 & 0,22570 & 0,56000 & 0,62926 & 0,12222 \\
2010 & 0,52267 & 0,43207 & 0,27044 & 0,68581 & 0,81056 & 0,12584 \\
2011 & 0,51537 & 0,40883 & 0,26131 & 0,77253 & 0,90000 & 0,13769 \\
2012 & 0,44895 & 0,39241 & 0,23092 & 0,76540 & 0,74927 & 0,17354 \\
2013 & 0,40330 & 0,47328 & 0,23757 & 0,79055 & 0,68550 & 0,17950 \\
2014 & 0,38891 & 0,47725 & 0,22923 & 0,77844 & 0,65460 & 0,18333 \\
2015 & 0,46251 & 0,53656 & 0,20750 & 0,69237 & 0,67790 & 0,19703 \\
\hline Target & 0,49521 & 0,56467 & 0,16649 & 0,65862 & 0,64804 & 0,20306 \\
\hline
\end{tabular}

Hasil normalisasi data testing dapat dilihat pada Tabel 3. Data ini juga telah dinormalisasi menggunakan rumus normalisasi seperti yang dijelaskan pada Persamaan (1) berdasarkan pada Tabel 1, yakni tahun 2005-2015 dengan target tahun 2016.

\section{Hasil dan Pembahasan}

Model arsitektur jaringan yang digunakan pada penelitian ini ada 5 arsitektur, antara lain 12-5-1, 12-71, 12-8-1, 12-10-1 dan 12-14-1. Berdasarkan model arsitektur 12-5-1 dapat dijabarkan bahwa 12 merupakan data neuron input layer, 7 merupakan data neuron hidden layer dan 1 merupakan data neuron output layer. Begitu pula halnya dengan keterangan model arsitektur yang lain. 
Tabel 4 dapat dilihat komparasi dari masing-masing model arsitektur. Tingkat iterasi dan kecepatan waktu dari 5 model arsitektur dilihat dengan menggunakan aplikasi Matlab. Tingkat akurasi maupun nilai MSE (Mean Squared Error) dari ke 5 model arsitektur diperoleh menggunakan Microsoft Excel. Sebenarnya ada 2 model arsitektur yang sama-sama menghasilkan akurasi 83\%, yakni 12-5-1 dan 12-10-1. Hanya saja model arsitektur 12-5-1 lebih rendah epoch, waktu dan MSE nya. Sehingga penulis berkesimpulan dari masing-masing 5 model arsitektur diperoleh model arsitektur terbaik menggunakan 12-5-1.

Tabel 4. Hasil akurasi Backpropagation

\begin{tabular}{ccccccc}
\hline \multirow{2}{*}{ Pola } & \multirow{2}{*}{ Arsitektur } & \multicolumn{3}{c}{ Training } & \multicolumn{2}{c}{ Testing } \\
\cline { 2 - 7 } & & Epoch & Waktu & MSE & MSE & Akurasi \\
\hline 1 & $12-5-1$ & 2582 & $00: 20$ & 0,00099875 & 0,02816413 & $83 \%$ \\
2 & $12-7-1$ & 937 & $00: 07$ & 0,00099836 & 0,03536873 & $33 \%$ \\
3 & $12-8-1$ & 21154 & $02: 57$ & 0,00099875 & 0,13335481 & $50 \%$ \\
4 & $12-10-1$ & 2820 & $00: 37$ & 0,00099969 & 0,00256091 & $83 \%$ \\
5 & $12-14-1$ & 1145 & $00: 09$ & 0,00099903 & 0,01124036 & $67 \%$ \\
\hline
\end{tabular}

Secara garis besar parameter maupun struktur jaringan Backpropagation yang digunakan dalam penelitian ini di proses dan dilatih menggunakan aplikasi Matlab. Secara umum kode program yang diberikan untuk membentuk struktur jaringan Backpropagation seperti pada Tabel 5.

Tabel 5. Potongan kode program untuk membentuk struktur jaringan Backpropagation menggunakan Matlab > net=newff(minmax(P),[Hidden,Target],\{'tansig','purelin'\},'traingd');

//Perintah ini untuk membentuk jaringan Backpropagation dengan neuron hidden 5, 7, 8, 10 dan 14 dengan output 1. Fungsi aktivasi yang digunakan adalah tansig (sigmoid bipolar) dan purelin (linier) serta fungsi pelatihan traingd (Gradient Descent).

$\gg$ netIW $\{1,1\}$;

// Perintah ini untuk melihat nilai bobot awal pada lapisan masukan dan lapisan tersembunyi (bilangan diambil secara acak dari komputer).

$>$ netb $\{1\}$;

// Perintah ini untuk melihat nilai bias pada hidden layer/lapisan tersembunyi (bilangan diambil secara acak dari komputer).

>netLW\{2,1\};

// Perintah ini untuk melihat nilai bobot pada hidden layer/lapisan tersembunyi dan output layer/lapisan keluaran (bilangan diambil secara acak dari komputer).

$\gg n e t b\{2\}$;

// Perintah ini untuk melihat nilai bias pada output layer/lapisan keluaran (bilangan diambil secara acak dari komputer).

> nettrainparamepochs=100000;

// Perintah untuk menentukan jumlah epochs maksimum pelatihan, yakni sebesar 100000.

> nettrainparamLR=001;

//Perintah untuk menentukan laju pembelajaran Learning rate yang digunakan pada penelitian ini sebesar 0,01 .

> nettrainParamgoal $=0001$;

//Perintah untuk menentukan batas MSE agar iterasi dihentikan. Goal yang digunakan sebesar 0,001.

> nettrainParamshow $=1000$;

// Perintah untuk menampilkan frekuensi perubahan MSE.

$>$ net $=$ train $($ net $, P, T)$

//Perintah untuk melatih jaringan berdasarkan perintah-perintah yang telah dimasukkan sebelumnya.

Kode program yang telah dimasukkan kedalam Matlab, akan menghasilkan pelatihan jaringan saraf (Neural network training) yang dapat dilihat pada Gambar 3, Gambar 4, Gambar 5, Gambar 6 dan Gambar 7. Gambar 3 sampai dengan Gambar 7 dapat diketahui bahwa yang merupakan hasil data training terbaik terdapat pada Gambar 3 dengan menggunakan model arsitektur 12-5-1 yang diperoleh dengan menggunakan aplikasi Matlab. Pada Gambar 3 dapat dilihat epoch yang terjadi sebesar 2582 iterasi dengan waktu 20 detik. Gambar 4 merupakan hasil data training dengan arsitektur 12-7-1 yang menghasilkan epoch sebesar 937 iterasi dengan waktu 7 detik. Gambar 5 merupakan hasil data training dengan arsitektur 12-8-1 yang menghasilkan epoch sebesar 21154 iterasi dengan waktu 2 menit 57 detik. 


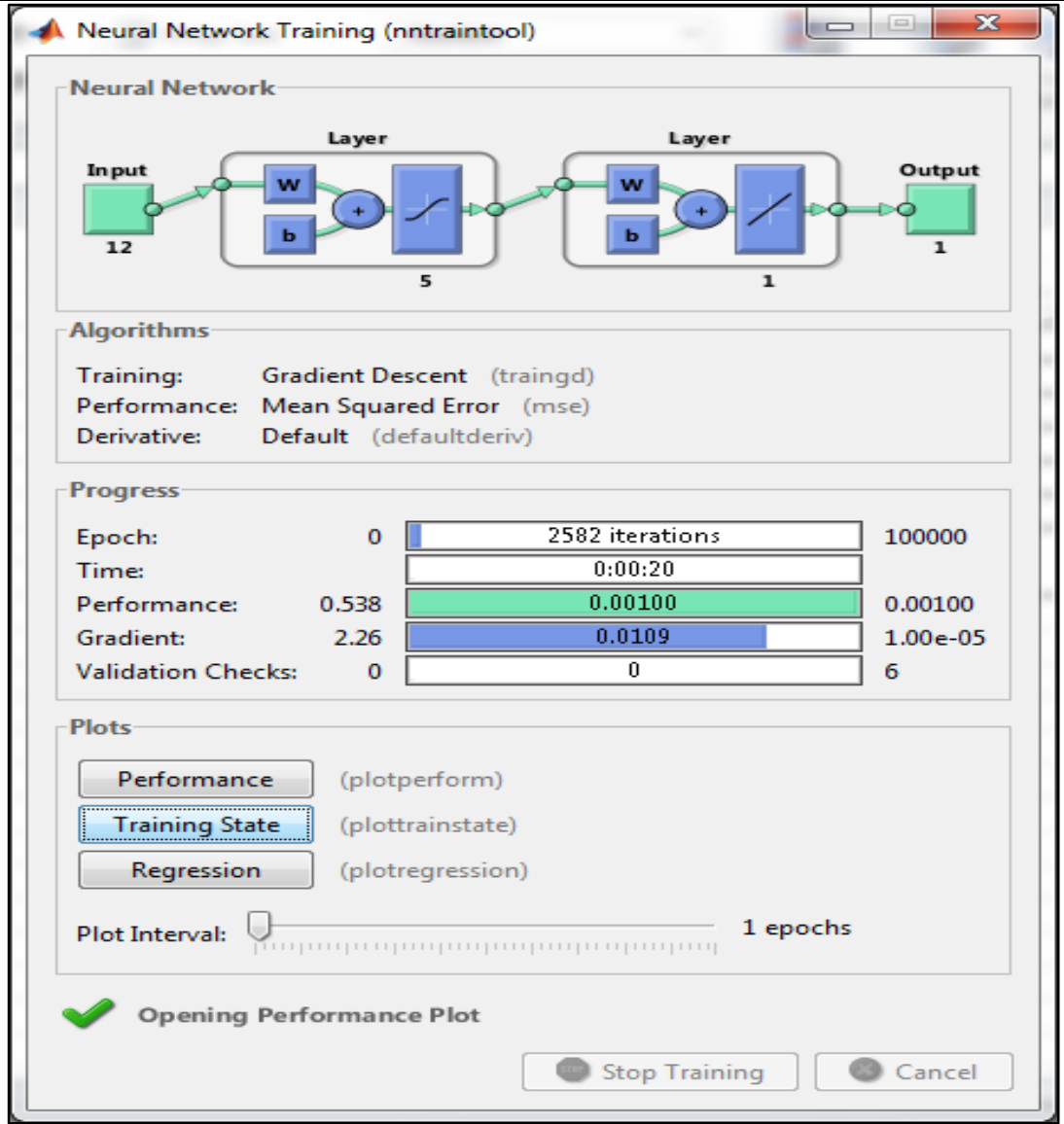

Gambar 3. Hasil data training terbaik dengan arsitektur 12-5-1

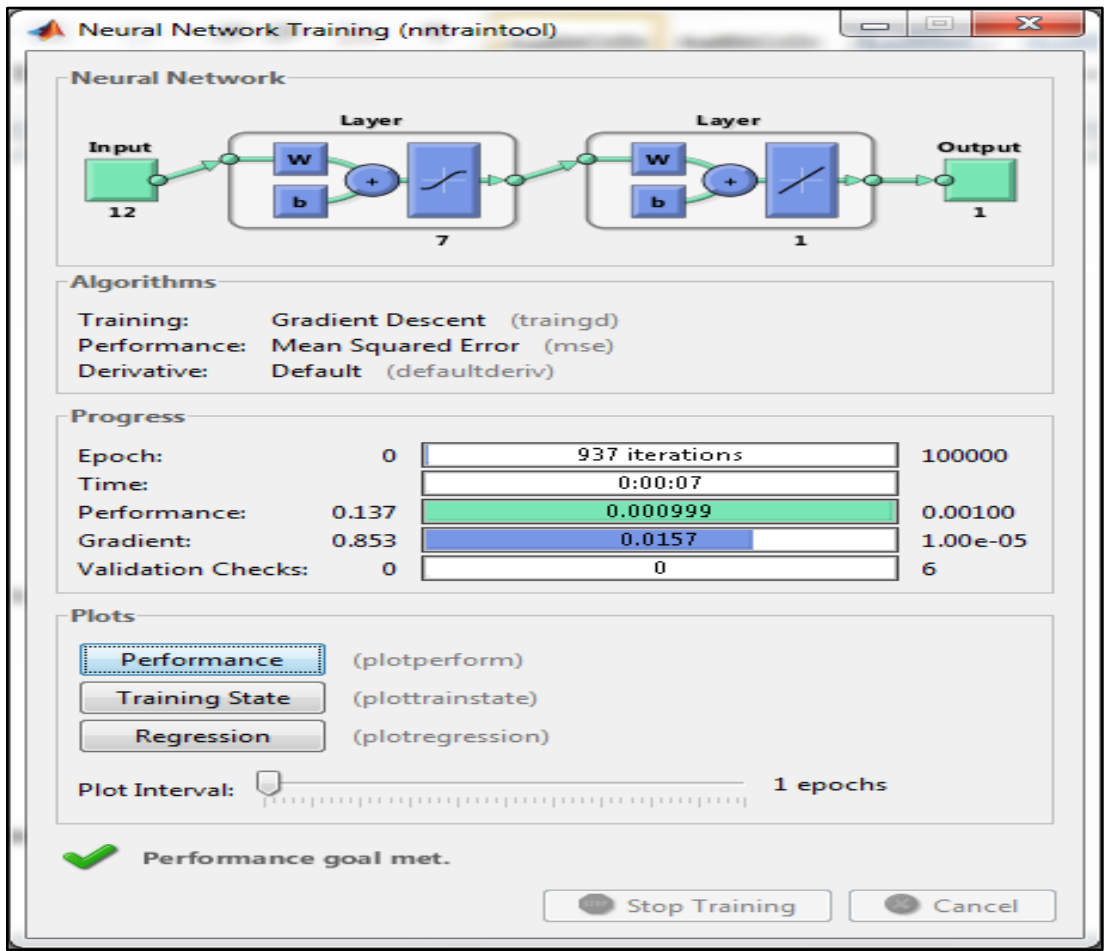

Gambar 4. Hasil data training dengan arsitektur 12-7-1

Tabel 6 merupakan hasil akurasi dan tingkat MSE dari model arsitektur terbaik, yakni 12-5-1. Perhitungan dan pembuatan Tabel 6 menggunakan Microsoft Excel. Berdasarkan Tabel 6, error diperoleh dari Target-Output, Sum of Squared Errors (SSE) diperoleh dari nilai error ${ }^{2}$, total adalah jumlah SSE yang dihasilkan dari pola 1 ke pola 6 , hasil adalah jika nilai kesalahan dalam pengujian data $<=0,05$ 
maka hasilnya benar (1), jika tidak maka salah (0). Akurasi diperoleh dari jumlah hasil yang benar pada $\frac{\text { pola }}{6} \times 100$, menghasilkan $83 \%$, margin error diperoleh dari jumlah hasil yang salah $\frac{\text { pola }}{6} \times 100$ atau diperoleh dari jumlah akurasi maksimum 100\% dikurangi akurasi yang dihasilkan, menghasilkan $17 \%$. MSE diperoleh dari total $\frac{S S E}{6}$ (jumlah pola), 1 berarti benar dan 0 berarti salah.

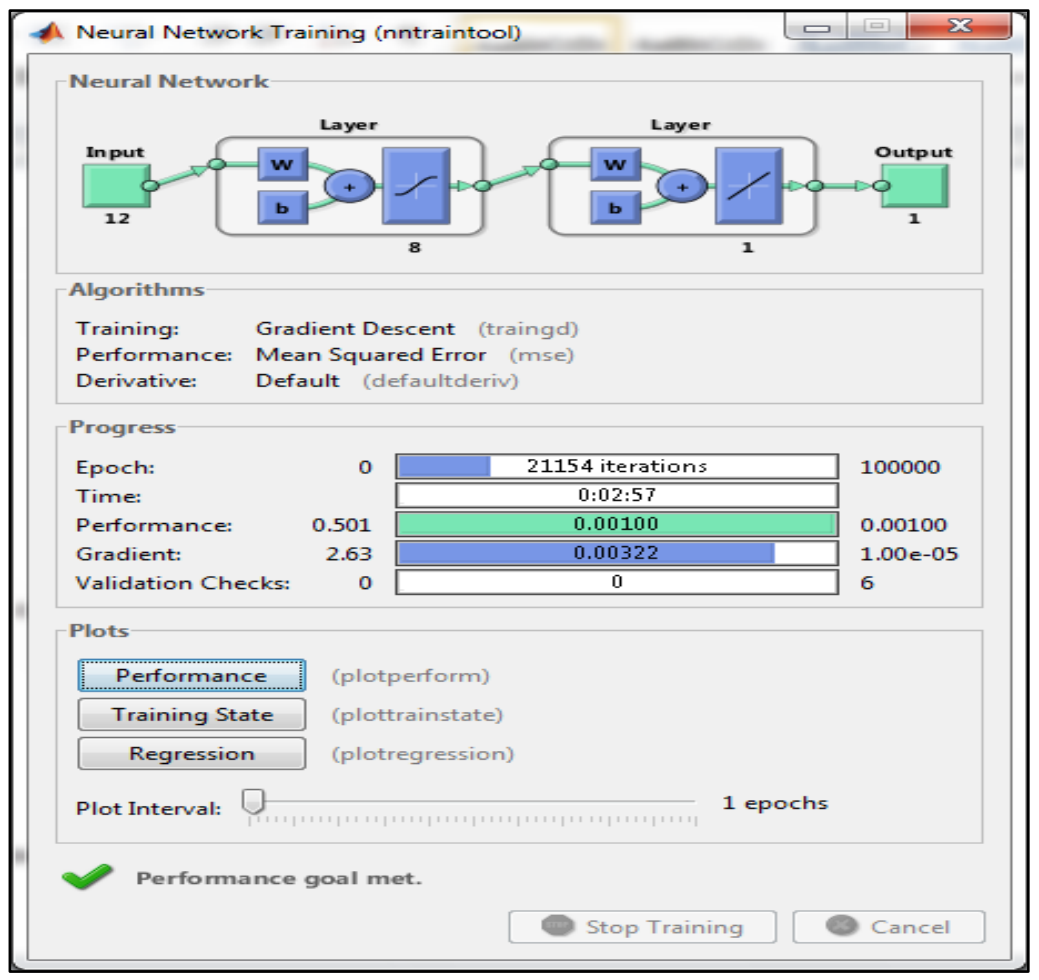

Gambar 5. Hasil data training dengan arsitektur 12-8-1

Tabel 6. Arsitektur Backpropagation Terbaik dengan Model 12-5-1

\begin{tabular}{cccccccccc}
\hline \multirow{2}{*}{ Pola } & \multicolumn{4}{c}{ Data Training } & \multicolumn{5}{c}{ Data Testing } \\
\cline { 2 - 10 } & Target & Output & Error & SSE & Target & Output & Error & \multicolumn{1}{c}{ SSE } & Hasil \\
\hline 1 & 0,47427 & 0,51030 & 0,03603 & 0,00130 & 0,49521 & 0,57280 & $-0,07759$ & 0,00602 & 1 \\
2 & 0,36167 & 0,33510 & 0,02657 & 0,00071 & 0,56467 & 0,78350 & $-0,21883$ & 0,04789 & 1 \\
3 & 0,21748 & 0,20340 & 0,01408 & 0,00020 & 0,16649 & 0,24240 & $-0,07591$ & 0,00576 & 1 \\
4 & 0,55958 & 0,53500 & 0,02458 & 0,00060 & 0,65862 & 0,60650 & 0,05212 & 0,00272 & 0 \\
5 & 0,52778 & 0,50980 & 0,01798 & 0,00032 & 0,64804 & 0,97360 & $-0,32556$ & 0,10599 & 1 \\
6 & 0,10690 & 0,16040 & 0,05350 & 0,00286 & 0,20306 & 0,22780 & $-0,02474$ & 0,00061 & 1 \\
\hline & & Total & 0,00599 & & & Total & 0,16898 & \multirow{2}{*}{$83 \%$} \\
& & & MSE & 0,000999 & & & MSE & 0,028164 & \\
\hline
\end{tabular}

Gambar 6 merupakan hasil data training dengan arsitektur 12-10-1 yang menghasilkan epoch sebesar 2820 iterasi dengan waktu 37 detik. Gambar 7 merupakan hasil data training dengan arsitektur 12-14-1 yang menghasilkan epoch sebesar 1145 iterasi dengan waktu 9 detik.

Tabel 7 dapat dilihat hasil prediksi volume ekspor dan impor migas di Indonesia untuk 4 tahun ke depan, yakni tahun 2017-2020. Adapun hasil ini diperoleh dari perhitungan dengan model arsitektrur terbaik (12-5-1) menggunakan aplikasi Matlab dan Microsoft Excel, sama seperti pembahasan sebelumnya.

Gambar 8 dapat dijelaskan bahwa hasil prediksi untuk volume ekspor dan impor minyak mentah tahun 2017-2020 mengalami penurunan yang cukup signifikan dibandingkan tahun 2016. Sedangkan volume ekspor hasil minyak tahun 2017-2020 ada kecendrungan menguat, sedangkan impor mengalami penurunan. Untuk volume ekspor gas sendiri juga hampir sama seperti ekspor minyak mentah yang sama-sama mengalami penurunan yang cukup besar dibandingkan tahun 2016, sedangkan volume impor gas tahun 2017-2020 secara garis besar semakin meningkat dibandingkan tahun 1996-2016, sehingga sangat perlu diwaspadai, meskipun kenaikannya tidak terlalu besar. 


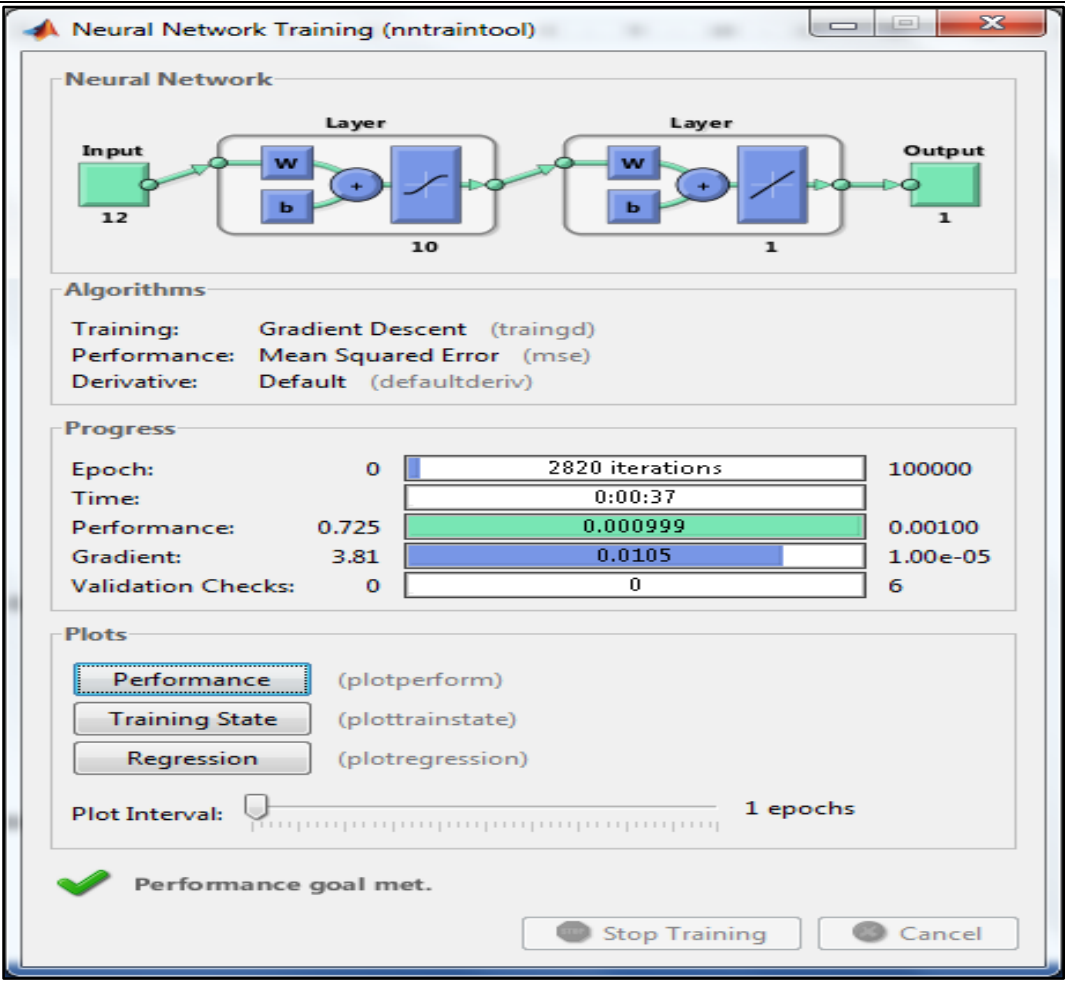

Gambar 6. Hasil data training dengan arsitektur 12-10-1

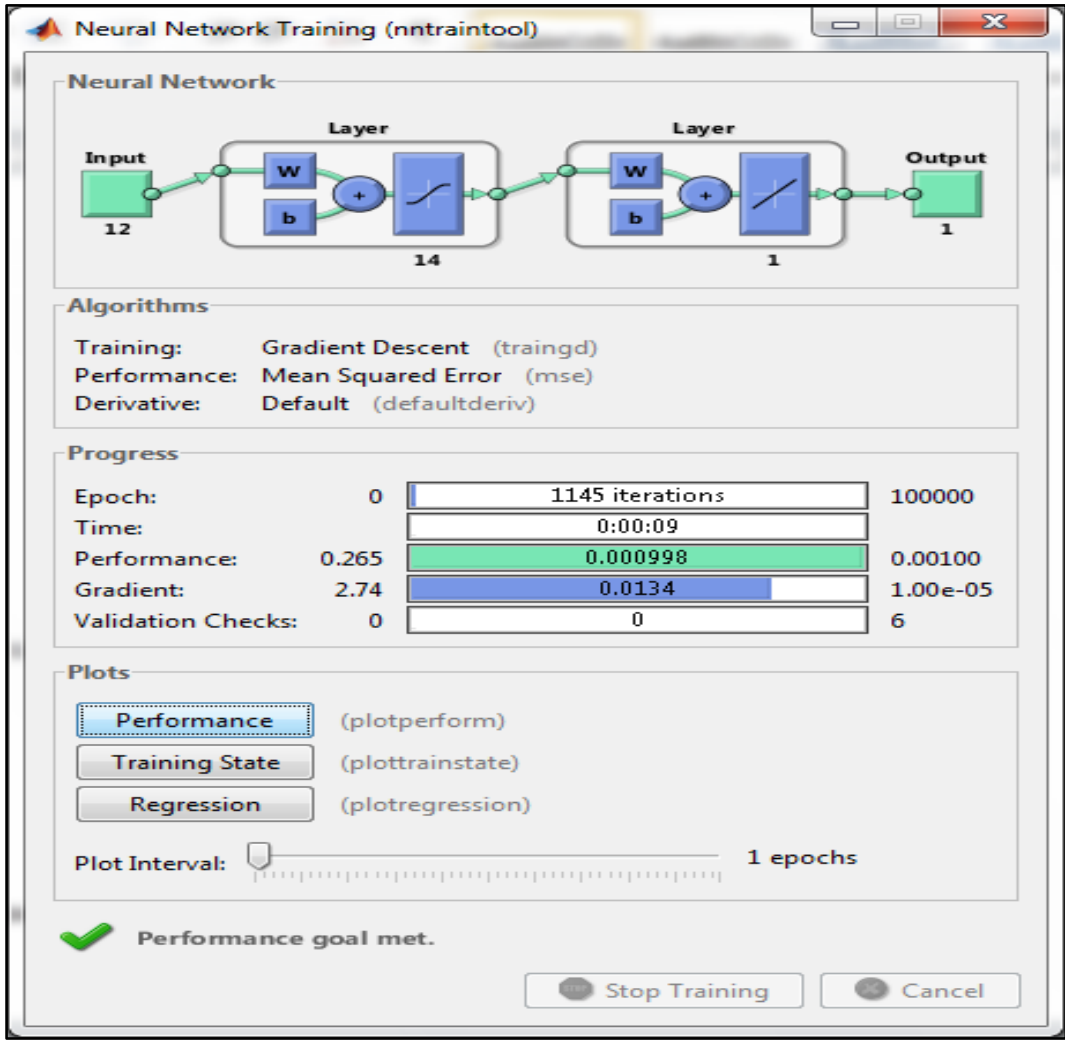

Gambar 7. Hasil Data Training dengan Arsitektur 12-14-1

Tabel 7. Hasil prediksi 4 tahun kedepan dengan Backpropagation (Ribu Ton)

\begin{tabular}{cccccrc}
\hline \multirow{2}{*}{ Tahun } & \multicolumn{2}{c}{ Minyak Mentah } & \multicolumn{2}{c}{ Hasil Minyak } & \multicolumn{2}{c}{ Gas } \\
\cline { 2 - 7 } & Ekspor & Impor & Ekspor & Impor & \multicolumn{1}{c}{ Ekspor } & \multicolumn{1}{c}{ Impor } \\
\hline 2017 & 13460,65 & 15382,50 & 3213,45 & 16977,44 & 17844,78 & 6777,70 \\
2018 & 9581,74 & 9045,86 & 5214,29 & 10042,62 & 11227,76 & 5512,40 \\
2019 & 6848,45 & 6740,96 & 5832,17 & 7299,46 & 6930,38 & 6458,32 \\
2020 & 6158,28 & 6067,67 & 6171,48 & 6157,17 & 6107,29 & 6020,72 \\
\hline
\end{tabular}




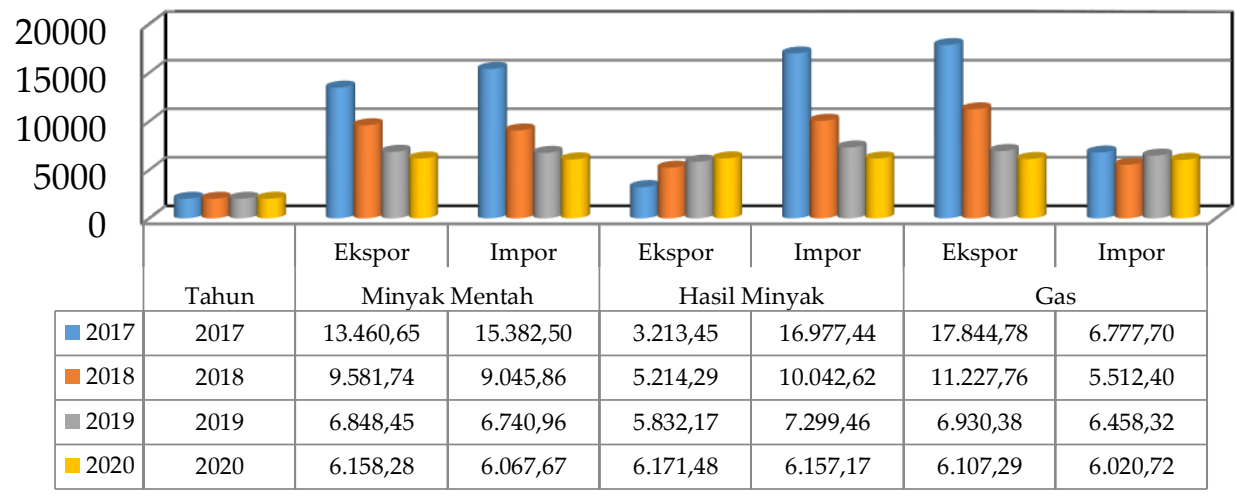

Gambar 8. Grafik prediksi ekspor dan impor migas 4 tahun selanjutnya (Ribu Ton)

\section{Kesimpulan}

Berdasarkan hasil penelitian mengenai volume ekspor dan impor migas di indonesia, maka dapat disimpulkan bahwa dengan model arsitektur 12-5-1, dapat melakukan prediksi dengan akurasi 83\%, dengan melihat hasil testing pada 5 percobaan. Dapat dilihat pada Tabel 4 bahwa kecepatan maupun hasil akurasi sangat bervariasi. Berdasarkan perbandingan data awal dan data hasil prediksi, dapat disimpulkan bahwa nilai ekspor migas semakin lama semakin menurun, sedangkan nilai impor migas semakin lama semakin tinggi. Hasil dari penelitian ini, diharapkan agar pemerintah dapat mengantisipasi meningkatnya volume ekspor dan impor migas.

\section{Referensi}

Alqurni, R. P., \& Muljono, M. (2016). Pengenalan tanda tangan menggunakan Metode Jaringan Saraf Tiruan Perceptron dan Backpropagation. Techno.com, 15(4), 352-363.

Annuri, I. F., \& Ruzikna, R. (2017). Analisis penggunaan metode Altman (Z-score) dalam memprediksi terjadinya financial distress pada perusahaan minyak bumi dan gas (Migas) yang terdaftar di Bursa Efek Indonesia (BEI) periode 2010-2014. Jurnal Online Mahasiswa Fakultas Ilmu Sosial dan Ilmu Politik Universitas Riau, 4(2), 1-13.

BPS, B. (2017). Volume Ekspor dan Impor Migas (Berat bersih: ribu ton), 1996-2016. Jakarta: Badan Pusat Statistik. Retrieved from https://www.bps.go.id/statictable/2017/11/20\%2000:00:00/1982/volumeekspor-dan-impor-migas-berat-bersih-ribu-ton-1996-2016.html

Hidayat, N. F., Musadieq, M. A., \& Darmawan, A. (2017). Pengaruh foreign direct investment, nilai tukar dan pertumbuhan ekonomi terhadap ekspor (studi pada nilai ekspor non migas indonesia periode tahun 2005-2015). Jurnal Administrasi Bisnis, 43(1), 172-179.

Huang, D., \& Wu, Z. (2017). Forecasting outpatient visits using empirical mode decomposition coupled with back-propagation artificial neural networks optimized by particle swarm optimization. PLoS ONE, 12(2), 1-17. doi:https://doi.org/10.1371/journal.pone.0172539

Izzah, A., \& Widyastuti, R. (2016). Prediksi Kelulusan Mata Kuliah Menggunakan Hybrid Fuzzy Inference System. Register: Jurnal Ilmiah Teknologi Sistem Informasi, 2(2), 60-67.

Rumokoy, N. K. (2016). Pelanggaran hukum terhadap penggunaan minyak dan gas bumi (migas) yang terkandung di dalam wilayah hukum pertambangan Indonesia oleh pihak yang tidak berwenang. Jurnal Hukum Unsrat, 22(5), 40-55.

Sedyaningrum, M., Suhadak, S., \& Nuzula, N. F. (2016). Pengaruh Jumlah Nilai Ekspor, Impor Dan Pertumbuhan Ekonomi Terhadap Nilai Tukar Dan Daya Beli Masyarakat Di Indonesia Studi Pada Bank Indonesia Periode Tahun 2006:iv-2015:iii. Jurnal Administrasi Bisnis (JAB), 34(1), 114-121.

Setiawan, T. U., Taufiq, A., \& Astrika, L. (2017). Pemberdayaan masyarakat berbasis koperasi pada tambang minyak tradisional desa Bangoan kecamatan Jiken kabupaten Blora. Journal of Politic and Government Studies, 6(4), 111-120.

Siregar, S. P., \& Wanto, A. (2017). Analysis of Artificial Neural Network Accuracy Using Backpropagation Algorithm In Predicting Process (Forecasting). International Journal Of Information System \& Technology, 1(1), 34-42. 
Sumijan, S., Windarto, A. P., Muhammad, A., \& Budiharjo, B. (2016). Implementation of Neural Networks in Predicting the Understanding Level of Students Subject. International Journal of Software Engineering and Its Applications, 10(10), 189-204.

Wang, Z.-H., Gong, D.-Y., Li, X., Li, G.-T., \& Zhang, D.-H. (2017). Prediction of bending force in the hot strip rolling process using artificial neural network and genetic algorithm (ANN-GA). The International Journal of Advanced Manufacturing Technology, 93(9-12), 3325-3338.

Wanto, A., Windarto, A. P., Hartama, D., \& Parlina, I. (2017). Use of Binary Sigmoid Function And Linear Identity In Artificial Neural Networks For Forecasting Population Density. International Journal Of Information System \& Technology, 1(1), 43-54. 